\title{
Notas sobre a poética schopenhaueriana
}

\author{
BRUNO VICTOR BRITO PACÍFICO *
}

\begin{abstract}
RESUMO Este artigo tem a pretensão de apresentar a poética de Arthur Schopenhauer. Neste texto há uma investigação acerca da poesia na analise filosófica da arte, presente no livro terceiro de sua obra magna, intitulada O mundo como vontade e como representação. Em minha investigação também tratei de incluir alguns textos paralelos a esta obra, cuja discussão sobre a poesia e seus diversos gêneros também são de suma importância para a compreensão da poética schopenhaueriana. O principal motivo para a existência deste artigo é mostrar porque Schopenhauer é citado como uma das principais influências de alguns nomes importantíssimos da literatura. Vemos entre os grandes nomes os escritores Machado de Assis, Augusto dos Anjos, Jorge Luis Borges, Macedônio Fernandes, Thomas Mann, entre outros.
\end{abstract}

PalaVras-chave Ideia; Poesia; Humanidade.

NESTE ARTIGo apresento as questões fundamentais sobre a poesia e a sua forma elevada dentro do quadro geral das artes. Explicito o papel da poesia na teoria metafísica das artes schopenhaueriana. Mostrarei também alguns de seus gêneros para melhor exemplificar a importância da forma poética diante de outras formas artísticas.

Para isto, devo apresentar a relação da poesia com a ideia, visto que esta forma é um dos meios capaz de nos comunicar a ideia de humanidade. A partir disto, devo mostrar o porquê de a poesia ser considerada a arte mais elevada dentro da hierarquia metafísica das artes.

* Mestre em Filosofia pelo PPG/UFF 


\section{A POESIA COMO FORMA DE EXPOSIÇÃO DA IDEIA DE HOMEM}

Devo lembrar que o principal objetivo de todo e qualquer artista (pintor, escultor, poeta) é comunicar uma ideia. Assim como o artista plástico busca expressar a ideia universal de alguma coisa, o poeta também tem a finalidade de comunicá-la. O poeta deve expressar o grau mais elevado de objetivação da vontade, isto é: a ideia de homem (ou humanidade). O poeta deve comunicar esta ideia ao ouvinte (ou leitor) de modo muito vivaz. Isto se dá de acordo com a mente poética que apreende a ideia daquilo que busca expor - lembrando que a apreensão da ideia se dá partir da intuição, assim como ocorre com as demais formas de arte. ${ }^{1}$

O que difere a poesia das demais formas de arte é que esta comunica a ideia de humanidade por meio de palavras, diferente, por exemplo, da pintura que comunica tal ideia por meio de imagens (cenas da vida). As palavras são os principais materiais da poesia que oferece ao escritor uma enorme extensão sobre aquilo que ele tem a intenção de expressar. Deste modo, quase todos os graus de objetivação da vontade são possíveis de serem expressos tanto num poema, quanto numa narração ou descrição dramática. ${ }^{2}$

Desta maneira, vemos que o homem, se exprime não só por meio de uma única exposição (imagem), isto é, não se exprime somente através de um rosto ou de uma figura simples. A poesia surge como uma forma artística capaz de exprimir a ideia de muitas coisas do mundo, mas que dá maior espaço (ou extensão) para expressar as ações e caracteres da humanidade. ${ }^{3}$ Isto quer dizer que o homem pode ser expresso de maneira ainda mais perfeita que as formas que a escultura humana ou a pintura histórica nos mostram.

Lemos numa poesia as diversas ações acompanhadas por afetos (paixões ou frustrações) e pensamentos da personagem (fictício ou não). As ações, os afetos e os pensamentos são os temas principais abarcados na poesia. O que há na arte poética, e o que falta às artes plásticas, é o desenvolvimento de eventos sucessivos. Deste modo, Schopenhauer reconhece que a poesia é a forma mais elevada na hierarquia das artes

1 SCHOPENHAUER, 2005, p. 320.

2 SCHOPENHAUER, 2003, p. 203.

3 JANAWAY, 1994, p. 102. 
porque não há outra forma de arte que possa realizar tudo isto de modo comparável. É por isto que o objeto por excelência da arte poética é a manifestação da ideia que correspondente ao grau mais elevado de objetivação da vontade, porque é a única forma capaz de expor o homem numa "séria concatenada de seus esforços e ações". ${ }^{4}$

Contudo, preciso explicitar como a poesia consegue comunicar a ideia a partir de conceitos abstratos (as palavras). Para Schopenhauer, esta comunicação com o sujeito que intui a ideia só é possível mediante a ajuda da fantasia (ou imaginação). Outro fator que ajuda na comunicação da ideia de humanidade é a intuição de representantes concretos de conceitos abstratos. ${ }^{5}$ Podemos dizer que o poeta utiliza os meios conceituais a fim de revelar a ideia de humanidade à imaginação do leitor de poesia ou drama.

A poesia é definida como a arte "de colocar em jogo o poder da imaginação através de palavras". ${ }^{6} \mathrm{~A}$ imaginação do leitor é um dos meios através dos quais a poesia apresenta as suas imagens. Compreendemos, portanto, que o escritor busca através do movimento de nossa imaginação (fantasia) revelar as ideias, isto é, nos mostrar como é a vida e também a essência do mundo. ${ }^{7}$

Existem alguns meios para que o escritor consiga pôr em atividade a imaginação do leitor. O primeiro se dá através da intenção do poeta de modificar as palavras, formando assim um modelo (representativo) a ser intuído pela fantasia do leitor. O representante intuitivo é resultado da reunião de palavras, principal matéria-prima da poesia ou da prosa. As palavras devem ser cruzadas, a fim de interromperem os seus significados universais, ligados a conceitos. Assim, o poeta obterá um modelo (representativo) para a intuição. A partir do modelo representativo é possível movimentar a imaginação do leitor, fazendo que ele produza imagens. Toda esta preocupação que o poeta deve ter com as palavras tem a ver com o fato de estas fazerem efeito imediato somente sobre a razão, e não sobre a nossa fantasia. Assim, afirmo que as palavras só fazem efeito sobre a fantasia de modo mediato. ${ }^{8}$

SCHOPENHAUER, 2003, p. 204.

5 SCHOPENHAUER, 2005, p. 320-321.

6 SCHOPENHAUER, 2014, p. 97.

7 Ibid., 2014, p. 98.

8 SCHOPENHAUER, 2003, p. 193-194. 
Schopenhauer afirma ${ }^{9}$ que pôr em movimentação a imaginação do leitor se dá de acordo com a construção intuitiva do exposto. Posso também denominar de expressão vivaz da exposição poética. O filósofo alemão explica que esta condição deve orientar o conceito para a nossa intuição. Isto é possível mediante a particularização do conceito abstrato universal. Neste sentido, este conceito universal deve se tornar uma palavra determinada e concreta, a ponto de ser utilizada na descrição narrativa de modo bastante simples, ou em poucas palavras. Contudo, o poeta deve ter certo zelo com a palavra escolhida para aquilo que vai escrever, pois é a descrição poética que deve fazer com que a imagem dela apareça em nossa imaginação. Isto se dá, principalmente, através da forma como o escritor descreve as ocorrências da vida, pois ele deve, por assim dizer, colorir a frieza do conceito e não narrar com vagueza um fato (ficcional ou não).

É importante a escolha e as modificações das palavras que o poeta faz, pois, como falei acima, é um meio de atingir a imaginação do leitor e assim possibilitar que este possa intuir a universalidade daquilo que o poeta tem intenção de expressar. A escolha da palavra deve ser sempre pontual, pois cada palavra tem uma designação importante na poesia. Desta forma, o poeta deve ter a capacidade de apreender o específico e, ao mesmo tempo, a essência íntima das coisas, e, a partir disto, expressar em seus escritos o que não é casual ou somente o comum da vida. Tudo aquilo que o poeta deve nos apresentar tem que ser de um modo único e sem excessos. Isto quer dizer que ele não precisa de muitas palavras para explicá-lo. Assim, Schopenhauer afirma: “sentimos exatamente o que foi dito e pintamos o inessencial de acordo com nosso humor". ${ }^{10}$

É interessante expor a analogia que Schopenhauer faz entre o poeta e o químico. Sobre a analogia, Schopenhauer diz:

Assim como o químico combina dois fluidos perfeitamente claros e transparentes e dessa combinação resulta um precipitado sólido, também o poeta, a partir da universalidade transparente e abstrata dos conceitos, sabe combiná-los e obter, por assim dizer, um precipitado concreto, individual, a representação

9 Ibid., 2003, p. 195.

10 SCHOPENHAUER, 2003, p. 199. 
intuitiva. [...] a maestria na poesia consiste em obter todas as vezes justamente o precipitado que se intencionava. ${ }^{11}$

Posso afirmar que ambos (o químico e o poeta) querem um resultado que satisfaça os seus objetivos. Deste modo, vemos que a palavra representativa é como um precipitado sólido que o químico busca. Tanto a palavra quanto o precipitado devem ser exatos, isto é, devem estar de acordo com a intenção que cada um busca em seus ofícios. Assim, o poeta deve escolher a palavra perfeita para o poema; no caso do químico, deve escolher o precipitado ideal para o seu experimento.

Devo, contudo, observar que uma das dificuldades que o escritor enfrenta tem a ver com a orientação do conceito universal para as palavras muito particulares. Schopenhauer diz que o escritor deve evitar as expressões mais comuns ou vulgares, pois vemos que todas as descrições que utilizam palavras muito específicas (conceitos particulares) acabam por descrever as coisas da vida de maneira muito simplista. Isso não condiz com o tipo de poeta genial que expressa sempre as coisas mais universais da humanidade. Vemos que as palavras mais universais conseguem representar as imagens da vida de maneira mais elevada. Ao escrever, o escritor tem a intuição da palavra perfeita para um poema, não devendo então utilizar aquela palavra que possui precisão conceitual específica.

Se, por um lado, abandona a vulgaridade e a especificidade de certas palavras, o escritor deve por outro elaborar descrições que não sejam abstratas, pois seu trabalho é apresentar algo concreto e, ao mesmo tempo, universal da vida. A título de exemplo, podemos expressar algo específico como "a noite está fria”. Porém, é mais interessante que o poeta descreva que "a noite está fria cortante", pois o específico (noite fria) sugere algo extremamente preciso sem assim nos oferecer uma imagem à imaginação, como a segunda descrição sugere.

Chamo a atenção para a poesia que expressa uma descrição de maneira simplista pode ser considerada ruim, pois este tipo de descrição pormenorizada suprime a potência do efeito poético. Quando há muitas palavras (conceitos) em um poema ou em uma prosa, elas acabam por nos manter na apreensão de um pensamento racional, dificultando a intuição e o efeito sobre o leitor que deve atingir as imagens universais pre- 
sentes no escrito. As poucas palavras devem exprimir pensamentos que despertem imagens vivazes e, ao mesmo tempo, intuitivas. Isto justifica a escolha cuidadosa das palavras pelos poetas. Estes devem equilibrar tal escolha, assim devem ser econômicos e dar preferência àquelas com significados profundos. As expressões poéticas devem, portanto, sempre mostrar uma precisão na descrição breve. ${ }^{12}$

O poeta nos apresenta algo em particular, entretanto, o que ele conhece e quer que nós também possamos conhecer é a ideia de homem presente em seus escritos. O escritor pode se basear na vida real para descrever com muita precisão aquilo que é particular (individual). É a partir desta particularidade descrita de forma precisa que a poesia nos revela a existência humana por inteiro. Podemos indicar que o poeta nos permite intuir o conhecimento da ideia de humanidade por meio do particular. Portanto, esta ideia nos é apresentada de maneira familiar à nossa imaginação. ${ }^{13}$

Devo também ressaltar dois outros meios que ajudam a poesia a desenvolver a sua interatividade com o leitor. Estes são a rima e o ritmo. Através destes meios, a poesia lida causa grande efeito sobre nossas faculdades ligadas ao tempo. Para Schopenhauer, toda a nossa maneira de criar representações (faculdade de representação) está ligada ao tempo. O ritmo só existe no tempo, sendo esta uma intuição a priori. Assim, Schopenhauer diz que o ritmo pertence à pura sensibilidade. Ao contrário disto, a rima é algo da sensibilidade empírica, pois se trata de uma forma que atinge a sensibilidade, isto é, nossa audição. ${ }^{14}$

Deste modo, seguimos de maneira interna e de bom grado os sons que retornam (em intervalos) de modo regular, como se consentíssemos com aquilo que estamos lendo. Observamos que são a rima e o ritmo que nos conduzem a uma profunda atenção a um poema. Esta atenção nos permite criar uma concordância com aquilo que nos é apresentado, visto que esta concordância é anterior a qualquer juízo e independente de qualquer fundamento. Isto quer dizer que a poesia adquire assim um poder de convencimento enfático. ${ }^{15}$

\footnotetext{
12 SCHOPENHAUER, 2003, p. 201.

13 SCHOPENHAUER, 2014, p. 100-101.

14 Ibid., 2014, p. 102.

15 SCHOPENHAUER, 2005, p. 322.
} 
Através do ritmo e da rima, o poeta tem a possibilidade de escrever e falar de tal maneira que de outro modo não conseguiria nos cativar. Se o poeta escrevesse em forma de prosa, o pensamento e a ação perderiam seu significado. São estes os elementos (rima e ritmo) que nos fazem ter encanto com a poesia. Podemos verificar que uma poesia que expressa alguma ação ou pensamento ingênuos não precisa mais do que um ritmo e uma boa rima para nos satisfazer. A arte dos versos tem essa capacidade de nos cativar porque a rima, quando bem realizada, nos excita a sensibilidade através do pensamento expresso no poema. Deste modo afirma Schopenhauer:

Mesmo pensamentos triviais obtêm um toque de importância através de ritmo e rima e neles florescem [...] Na verdade, até mesmo ideias distorcidas e falsas ganham uma aparência de verdade através de versificações. ${ }^{16}$

Segundo Schopenhauer ${ }^{17}$ a rima e o ritmo são muito importantes para a composição da poesia. Mesmo que estas técnicas sejam consideradas recursos simples, a rima e o ritmo são capazes de nos causar um efeito profundo. O filósofo alemão nos mostra que a imediata audição do som das palavras num verso obtém, através do ritmo e da rima, uma significação e plenitude em si mesmas. Assim, o verso deixa de ser um simples recurso como mera expressão de palavras. Podemos compreender que o verso rimado e ritmado tem que, como seu principal objetivo, agradar os nossos ouvidos. ${ }^{18}$ Assim, eles se tornam um tipo de música quando lemos em voz alta uma poesia.

Podemos ainda fazer a observação de que antes mesmo de compreendermos algum pensamento ou significado na poesia, a melodia dos versos pode capturar nossa atenção a tal ponto que nem precisamos entender o seu significado quando ouvimos a sua melodia. Podemos, inclusive, achar tipos de poesia cujo significado é a apreensão de sua melodia. Deste modo, podemos entender que a melodia dos versos é, em alguns casos, o principal objetivo de alguns poetas, deixando em segundo plano o seu sentido. Com isto, podemos afirmar que há poesias cujo significado ou sentido é a audição de sua melodia.

16 SCHOPENHAUER, 2014, p. 103.

17 Ibid., 2014, p. 104.

18 Neste sentido, observamos que o que se dá com o verso é muito parecido com o processo de recepção da música. 
Em relação à prioridade do uso destes recursos na escrita poética, Schopenhauer indica ${ }^{19}$ que há uma importância maior do ritmo em detrimento da rima. É com o ritmo que a poesia garante maior satisfação ao leitor, pois é o melhor recurso para convencer os nossos juízos e orientar leitor e ouvinte através do tempo. Para o filósofo, o ritmo já era um meio reconhecidamente importante desde os antigos, pois era um recurso considerado mais nobre e digno que a rima. A rima era vista pelos antigos como um recurso inferior e que correspondia a um meio utilizado pelas línguas (consideradas) bárbaras ${ }^{20}$.

A eficácia da rima se limita apenas a repetir um mesmo som. Ao repetir um som, este não possui um reforço com alguma sílaba que sustente a repetição seguinte. Ouvimos então que a frequente repetição de único som não se sustenta até o fim do poema. Assim que a última sílaba recebe um par que possa rimar com ela, o seu efeito rapidamente se esgota diante de nossa audição. Numa recorrência disto, num terceiro momento, o som atua mais uma vez como uma rima repetida, atinge a mesma nota anterior de maneira acidental. Ouvimos então que a primeira rima se liga à rima presente, mas sem combinar com completamente com esta. Logo, afirma Schopenhauer $^{21}$, a repetição não eleva o efeito na rima ${ }^{22}$, pois a primeira nota da rima não soa a partir das segunda e terceira notas, ocorrendo o que Schopenhauer chama de “pleonasmo estético".

No próximo item tratarei de exponho acerca de dois importantes gêneros da poesia. Primeiro mostro quais são os níveis de objetividade da ideia de humanidade em cada um dos gêneros. A partir disto, exponho os dois gêneros que Schopenhauer cita

19 SCHOPENHAUER, 2003, p. 203.

20 A partir das indicações de Schopenhauer, podemos observar que há regras da poesia que visam a utilizar mais a rima do que o ritmo. Algumas delas dizem as sílabas na rima têm de ser escritas da mesma maneira; o hiato entre as rimas não é permitido; há uma limitação na utilização de muitas palavras. Muitas destas regras objetivam atingir mais a satisfação de nossa visão do que a satisfação de nossa audição. Porém, não discutiremos este tópico neste momento, pois isto fugiria ao escopo do presente artigo.

21 SCHOPENHAUER, 2014, p. 105.

22 As rimas em oitavas, os sonetos e tercetos são ainda mais problemáticos quando o poeta não é genial. Pois estes tipos de rima exigem um esforço ainda maior de quem ouve estes recursos. De modo geral, são estas técnicas da rima que geram desprazer para com elas. Tais acúmulos de rima são as causas da tortura psíquica sob a qual às vezes lemos essas produções: portanto, o prazer poético sob tal esforço psíquico é impossível (SCHOPENHAUER, 2014, p. 105). 
como exemplos que melhor definem os níveis de objetivação da vontade, e que nos mostram os diversos graus da ideia de homem. Mostro no item seguinte as questões acerca da poesia lírica (canção) e da tragédia.

\section{OS NÍVEIS DE OBJETIVAÇÃo dA IDEIA DE HOMEM NOS DIFERENTES GÊNEROS DA POESIA}

Schopenhauer nos sugere que a poesia possui uma espécie de hierarquia de apresentação da ideia de homem que se dá de acordo com o nível de sua objetivação. Esta aparece em todos os gêneros poéticos, porém, cada gênero nos apresenta algum nível de objetivação desta ideia. Observamos que o nível de exposição da ideia em alguns gêneros pode apresentar mais o lado subjetivo ou nos apresentar o lado mais objetivo da ideia de humanidade. Deste modo, posso indicar que consideramos uma poesia como bela conforme o nível de objetivação da ideia de humanidade, sugerindo que a poesia pode ser subjetiva, mais ou menos subjetiva, mais ou menos objetiva e completamente objetiva.

Vejamos as duas maneiras de expor a ideia de homem. O poeta pode expor algo que corresponda à sua própria condição - a exposição é a expressão do próprio expositor -, ou o exposto é completamente distinto do expositor. Na primeira maneira, o poeta intui o seu estado e o descreve em sua poesia. Este tipo se insere no lado subjetivo de objetivação da ideia. A segunda maneira tem a ver com o máximo distanciamento entre o expositor e aquilo que é descrito. O poeta pode aparecer em menor ou maior grau na narrativa ou na descrição dramática. Por fim, o poeta se oculta por completo nos gêneros considerados mais objetivos. ${ }^{23}$

Devo me aprofundar na questão da lírica ou canção para que fique mais claro o nível de objetivação da ideia de humanidade que este gênero nos apresenta. O gênero lírico é considerado menos objetivo que a tragédia. Esta nos apresenta o nível mais objetivo da ideia de homem dentre os demais gêneros poéticos e, por isto, é o gênero mais apreciado por Arthur Schopenhauer. 
A poesia lírica ${ }^{24}$ é o primeiro gênero que aparece na hierarquia dos gêneros poéticos. Vemos que alguns poetas encontram o seu material (a ideia de homem), em si próprios. O resultado desta inspiração do poeta em si mesmo é a poesia lírica. Nela, a parte predominante é o lado subjetivo da objetivação da ideia, pois na lírica, ou canção, o expositor se mostra em sua exposição poética. Schopenhauer indica (2005, p. 328) que o poeta (ou cancioneiro) tem a capacidade de intuir seu próprio estado de sentimentos, sua consciência e assim objetivá-la, externá-la em forma de poema ou canção. Assim, afirma Julian Young ${ }^{25}$ que a subjetividade é uma parte essencial deste gênero.

Sobre as canções (poesia lírica) em si, elas são declamadas por poetas cujo ânimo está exaltado, seja por uma alegria ou tristeza, ou excitado por causa de uma paixão. Isto tem a ver com o querer da vontade presente no poeta. Este estado de ânimo preenche uma parte de sua consciência e, ao mesmo tempo, o poeta também enxerga aquilo que o circunda, isto é, a natureza ao seu redor. A partir do momento em que o cantor (poeta) tem consciência da natureza que o circunda, surge aí também uma consciência de si, fazendo com que apareça o estado de puro sujeito do conhecimento destituído de vontade. Assim, podemos entender que há uma oposição entre o desejo que se encontra carente de satisfação (o querer interrompido) e a calmaria da condição de puro sujeito do conhecimento. Logo, podemos observar que é através da sensação deste conflito, a oposição entre o desejo e a calma, que há no cantor a assim chamada condição lírica. ${ }^{26} \mathrm{O}$ poeta lírico, de modo literal ou metafórico, canta, por exemplo, sobre seu amor perdido. Nesta situação, ele sente uma emoção intensa e dá voz a esse

24 Podemos considerar a lírica (ou canção) um gênero fácil de recepção por parte do ouvinte (leitor), justamente porque o poeta ou cantor expressa um sentimento que qualquer um pode sentir. Em relação a isto, Schopenhauer abre uma exceção para a poesia lírica enquanto obra de arte autêntica. Explicamos no capítulo anterior que, para o filósofo, apenas o gênio é capaz de criar uma obra autêntica, contudo, no caso da poesia lírica qualquer pessoa pode, tendo como intermediários uma inspiração ou exaltação interior e um estímulo exterior, elevar as suas faculdades não racionais além da média comum, e com isto "produzir uma bela canção" (SCHOPENHAUER, 2005, p. 328). Portanto, para que qualquer pessoa faça uma boa canção, uma forma de arte autêntica, basta que a sua intuição seja vigorosa em um momento de exaltação e, assim, deve-se produzi-la de acordo com o estado lírico (SCHOPENHAUER, 2014, p. 211).

25 YOUNG, 2005, p. 121.

26 SCHOPENHAUER, 2003, p. 212. 
sentimento em forma de versos. ${ }^{27}$ Posso afirmar, portanto, que as canções são resultado da condição lírica do poeta.

Sobre o efeito estético da canção, Schopenhauer explica que quando o cantor (poeta) se encontra na condição lírica, ele também se encontra num estado de puro conhecimento. Deste modo, estas duas condições são transmitidas pelas canções, e ao ouvirmos uma delas, nos deixamos, mesmo que por um instante, ser elevados ao estado de contemplação. Tudo isto se dá em conjunto com a condição do poeta (cantor), pois assim como acontece com ele também nos redimimos perante o querer, abandonando os nossos desejos. Contudo, devo indicar que há momentos de transição entre o estado de contemplação e a satisfação do desejo. Sempre que nos lembramos de nossos desejos (o querer da vontade), nos afastamos do estado de contemplação. Porém, quando nos conscientizamos de algum belo espaço ao nosso redor, nos acalmamos. Com isto, nos libertamos novamente do querer, pois a calmaria momentânea "nos oferece o puro conhecimento destituído da vontade". ${ }^{28}$

Observamos que tanto o nosso querer quanto a intuição de um belo lugar se mesclam um com o outro na condição lírica e na canção. A impressão do exterior nos aparece como mero reflexo. A partir disto, esta impressão é comunicada ao cantor pelas afecções da vontade. O cantor não se satisfaz completamente com o sentimento de amor ou tristeza, mas, ao apreender uma bela paisagem, acaba por permanecer mais tempo no estado de conhecimento puro. ${ }^{29} \mathrm{~A}$ essência da poesia lírica está exatamente no fato de que, quando estamos na condição lírica, encontramos tanto o sujeito puro do conhecimento quanto o querer de modo tão distinto em nós. ${ }^{30}$ Assim, a canção é considerada autêntica quando ela nos apresenta a impressão do estado de ânimo que se encontra mesclado e, ao mesmo tempo, cindido no cantor. ${ }^{31}$

Antes de passar para as considerações sobre a tragédia, preciso indicar que a canção não possui qualquer finalidade de nos apresentar sequências lógicas em seu discurso. As canções estão mais propensas a nos expressar pensamentos imperfeitos, ou

27 YOUNG, 2005, p. 121.

28 SCHOPENHAUER, 2003, p. 212.

29 SCHOPENHAEUR, 2003, p. 213.

30 Ibid., 2003, p. 213.

31 SCHOPENHAUER, 2005, p. 330. 
lacunares. A unidade expressa em sua forma é fundamentada pela sensibilidade e pelo humor, que tomam o lugar de qualquer tipo de discurso racional. Deste modo, as canções nos apresentam um fio de condução às diversas sequências que mudam rapidamente as imagens de nossa contemplação. ${ }^{2}$

Apesar de todo efeito e complexidade da poesia lírica, vemos que a poesia épica e o drama são gêneros mais objetivos. A épica é o gênero intermediário entre a lírica e o drama. Embora seja um gênero mais objetivo que a canção, esta forma poética ainda apresenta o lado subjetivo da ideia de humanidade. Podemos observar que o elemento subjetivo e objetivo se sobressaem simultaneamente, tendo a sua expressão de acordo com o tom e a forma como são apresentados pelo escritor. Assim, nós ainda podemos ver o poeta presente na narrativa, coisa que acontece um pouco menos com o drama. ${ }^{33}$ Não podemos ver tanto a presença do escritor na narrativa dramática porque este é um gênero que representa a humanidade de modo mais objetivo. ${ }^{34}$

Para Schopenhauer, a tragédia é um gênero poético ainda mais elevado que ambos os gêneros citados acima, tanto do ponto de vista da dificuldade de sua elaboração quanto de seu efeito sobre nós. ${ }^{35}$ Devo salientar que a tragédia é o gênero que representa a ideia de humanidade de maneira completamente objetiva. Isto quer dizer que em nenhum momento o poeta se utiliza da subjetividade para a realização de sua peça trágica, pois, de maneira genial, o poeta intui a ideia de homem.

Schopenhauer não é o único a pensar que a tragédia é uma forma de arte superior. Contudo, esta forma tem uma característica específica pela qual o filósofo se interessa: a de reproduzir a vida do homem naquilo que reflete as tonalidades verdadeiras da existência que apresenta em seu conteúdo os conflitos, o sofrimento não aliviado e os desejos não realizados. ${ }^{36} \mathrm{O}$ objetivo deste elevado e complexo gênero poético é nos apresentar a vida como algo terrível; mostrar a nossa existência num mundo cruel que nos faz sofrer. Além disto, esta forma poética tem a capacidade de nos apresentar o conflito da vontade em sua essência. Em outras palavras, nos apresenta o conflito

32 SCHOPENHAUER, 2014, p. 107.

33 Ibid., 2014, p. 108.

34 JANAWAY, 1994, p. 103.

35 SCHOPENHAUER, 2005, p. 333.

36 JANAWAY, 1994, p. 103. 
da vontade consigo mesma que se repercute nas ocorrências da vida humana. Assim, podemos ver que a tragédia tem a capacidade de representar a essência da vida através de uma encenação no palco. Deste modo, Schopenhauer afirma:

O objetivo dessa suprema realização poética não é outro senão a exposição do lado terrível da vida, a saber, o inominado sofrimento, a miséria humana, o triunfo da maldade, o império cínico do acaso, a queda inevitável do justo e do inocente. E em tudo isso se encontra uma indicação significativa da índole do mundo e da existência. ${ }^{37}$

Schopenhauer tece alguns comentários sobre as técnicas de criação da tragédia. Estas se baseiam em um princípio: apresentar a infelicidade humana. O filósofo desenvolve uma classificação dos tipos de apresentação da infelicidade. A primeira maneira de apresentá-la é a que nos mostra um caráter completamente maldoso que promove toda a infelicidade do herói. A segunda maneira tem a ver com a infelicidade causada pelo destino, acaso ou erro. A terceira e última maneira de apresentação da infelicidade tem a ver com as relações e as combinações das personagens que não precisam ter caracteres de maldade além da média, nem as situações precisam conter em sua trama algum erro, um acaso. Este tipo de apresentação da infelicidade precisa apenas de caracteres comuns que observamos na vida, em relação aos aspectos morais, nas circunstâncias que são dispostas de acordo com as situações com que nos deparamos. Aí se encontra o motivo pelo qual somos mais comovidos por este tipo de técnica, visto que a grande infelicidade está muito próxima de nós. Aquelas duas primeiras técnicas nos apresentam a ameaça da infelicidade humana de modo distante. Isto me permite indicar que a terceira técnica supera as duas anteriores por apresentar sofrimentos tão semelhantes aos da vida real. Como podemos observar no cotidiano, nas relações humanas temos diferenças com o próximo que podem ocasionar oposições que muitas vezes têm a ver com nossos próprios interesses, gerando a mesquinharia. É deste modo que começamos a desejar a desgraça de nosso próximo. ${ }^{38}$

Esta terceira técnica, sem dúvida, é muito mais difícil de ser realizada do que aquelas duas primeiras mencionadas acima. Schopenhauer afirma que o poeta precisa escolher e caracterizar bem cada personagem e situação. Pois são os arranjos da diversi-

37 SCHOPENHAUER, 2005, p. 333.

38 SCHOPENHAUER, 2005, p. 334-335. 
dade de situações e os caracteres de cada personagem que, quando bem executados, desencadeiam a força da trama e garantem, no fim da tragédia, um efeito poderoso sobre o espectador. ${ }^{39}$ A catástrofe que ocorre neste tipo de tragédia se realiza no decurso de uma vida comum, sem que o protagonista tenha feito algo extremamente ruim. Com isto, vemos que este tipo de técnica nos mostra a força de destruição da felicidade humana de tal maneira que o caminho pelo qual a tragédia nos conduz nos leva até a nossa própria condição de vida. ${ }^{\circ 0} \mathrm{O}$ prazer ao vermos uma peça trágica deste tipo produz em nós uma resignação perante aquilo que estamos vendo, ao mesmo tempo em que nos dá a possibilidade de vermos algo além da realidade aparente. ${ }^{41}$

Segundo Schopenhauer, esta terceira técnica é mais bem aplicada pelos modernos, e funda sua superioridade frente aos antigos. A tragédia moderna é superior precisamente porque deixa transparecer melhor a ideia de resignação ${ }^{42}$, a qual é raramente expressa de maneira direta na tragédia antiga. ${ }^{43}$ A questão para Schopenhauer é justamente a expressão da resignação. O importante para o filósofo alemão é o sentimento causado pela tragédia, isto é, o mais importante é termos em vista o abandono da própria vontade de viver. ${ }^{44}$ Os antigos viam a questão da resignação como algo secundário, que às vezes nem sequer aparecia em suas tragédias. Isto é explicado na medida em que a resignação é caracterizada como algo cristão, pois é com o cristianismo que a ideia de renúncia ao querer-viver aparece na história do pensamento. A tragédia cristã nos apresenta um herói que renuncia à vontade de viver porque tem consciência da ausência de valor da vida. Para os antigos, a tragédia deveria apresentar os homens sob o domínio do acaso e do erro sem, contudo, mostrar que a renúncia de seus heróis trágicos nos causa algum sentimento de redenção ou resignação diante da vida. Isto se dá porque os dramaturgos antigos não haviam conhecido o ápice de desenvolvimento objetivo da tragédia que só os modernos conheceram. ${ }^{45}$

39 SCHOPENHAUER, 2003, p. 225.

40 JANAWAY, 1994, p. 104.

41 DIAS, 2010, p. 116.

42 Ibid., 2010, p. 117.

43 Schopenhauer observa que na tragédia grega não podemos ver muitos exemplos de heróis que se resignam perante a vida.

44 SCHOPENHAUER, 2014, p. 210.

45 SCHOPENHAUER, 2014, p. 110-111. 
Vemos que a humanidade é como um reflexo do conflito da vontade consigo mesma. Assim que nos deparamos com o sofrimento ou a infelicidade humana, eles se tornam formas visíveis aos nossos olhos. A maneira pela qual o dramaturgo (poeta) disponibiliza as personagens e as situações é capaz de nos mostrar a perversão de todos os homens. É nesta encenação da vilania humana que o conhecimento da ideia de humanidade - em seu ápice - nos é comunicado. Assim, quando assistimos uma peça de teatro, obtemos consciência de tal vilania e crueldade dos homens e somos purificados, através do sofrimento da personagem (herói trágico). Isto nos possibilita que não mais tenhamos ilusão com a vida. Enxergamos no herói nosso próprio egoísmo. Isto quer dizer que nos tornamos capazes de enxergar que somos regidos pelo princípio de individuação. Através da expiação do sofrimento de existir, os motivos que antes faziam efeito sobre nós perdem as suas influências. Deste modo, o conhecimento da essência da vida produz uma renúncia de querer viver, retiramos assim o "véu de Maia” da representação. ${ }^{46}$ Dispor aos nossos olhos que devemos nos afastar da vida é a verdadeira tendência da tragédia, propósito no qual a intenção da apresentação dos sofrimentos humanos existe mesmo quando a resignação não é evidenciada pelo herói, mas apenas estimulada em nós, espectadores, com a visão do grande sofrimento merecido ou não. ${ }^{47}$

O que almejamos está muito além da tristeza, da dor e do sofrimento que são encenados na tragédia. Para Schopenhauer, o sentido da tragédia é que tenhamos um momento de serenidade após abandonarmos a vontade. O efeito da tragédia é uma pequena amostra da infelicidade e pode nos indicar um caminho de vida mais elevado que nós, como espectadores, podemos alcançar na vida real. ${ }^{48} \mathrm{O}$ sentido da tragédia é o de nos possibilitar a expiação das mazelas da vida e, a partir disto, nos fazer sentir que devemos ter desapego a ela. É exatamente isto que vemos ao fim de alguma obra deste gênero, ao observarmos que os heróis, após passarem por longas batalhas e sofrimentos, desistem dos seus objetivos que perseguiam perseverantemente, e também abdicam dos prazeres da vida. Deste modo, Schopenhauer afirma que o "sentido verdadeiro da

46 SCHOPENHAUER, 2005, p. 333.

47 SCHOPENHAUER, 2014, p. 112.

48 JANAWAY, 1994, p. 104. 
tragédia reside na profunda intelecção de que os heróis não expiam os seus pecados individuais, mas o pecado original, isto é, a culpa da existência mesma". ${ }^{49}$

\section{A POESIA E A HISTÓRIA}

O leitor deste artigo pôde compreender em minha exposição que a poesia não é a única forma de apresentação da vida do homem em todas as suas relações. Schopenhauer nos indica o fato de que há outras formas de conhecer o homem em seus esforços e ações na vida, a saber: a partir da experiência efetiva (práticas cotidianas) e a partir da história. Podemos ver que tanto a poesia e quanto a história se baseiam na experiência pessoal para elaborar seus respectivos conteúdos. ${ }^{50}$ No entanto, afirmo que mesmo que o dever da poesia e da história seja o de revelar a vida do homem, ou mesmo que a poesia e a história pareçam ter algo em comum - pois ambas têm por objeto o homem - elas o examinam através de ângulos diferentes. ${ }^{51}$

Podemos observar que a história e a experiência apenas nos permitem conhecer os homens de modo empírico. A consideração schopenhaueriana sobre estas nos mostra que através destas formas podemos apenas conhecer os homens de maneira exterior e isoladamente. Isto é, a história e a experiência não nos apresentam o homem em sua natureza essencial. A mera observação superficial que estas formas nos permitem ter da vida do homem apenas nos garante retirar delas as regras de comportamento e convívio, sacrificando assim nossa observação profunda acerca da sua essência..$^{22}$ A poesia, afirma o filósofo de Frankfurt, está para a história assim como a pintura de retrato está para a pintura histórica. A primeira nos apresenta sempre algo que corresponde ao universal, já a história nos apresenta a verdade a partir do que é particular e limitado ao fenômeno. 53

A partir do que foi escrito no parágrafo acima, posso indicar ao leitor que observe as diferenças cruciais de exposições da vida do homem que estas duas formas apresentam. Irei explicitar estas diferenças. A poesia recorre à intuição da ideia univer-

\footnotetext{
49 SCHOPENHAUER, 2005, p. 334.

50 SCHOPENHAUER, 2005, p. 322-323.

51 BOSSERT, 2011, p. 217.

52 SCHOPENHAUER, 2003, p. 204.

53 SCHOPENHAUER, 2005, p. 323.
} 
sal para nos apresentar o que se dá com todos (da espécie humana) e em todas as épocas. A história, ao contrário, nos apresenta algum fato a partir dos fenômenos particulares. Isto nos permite verificar na própria realidade a ocorrência daquilo que é relatado por ela. Assim, o historiador exprime os acontecimentos de acordo com a significação a partir do dado exterior (da aparência fenomênica). Seu valor de verdade se fundamenta a partir das relações e das consequências. Neste sentido, o historiador só consegue exprimir aquilo que mostra alguma relação entre fenômenos, ou alguma influência exterior de alguém importante em suas considerações sobre determinada época. O poeta, ao contrário, somente exprime os caracteres e situações a partir de escolhas definidas e com a intenção de nos mostrar algo significativo. Assim, ele só expõe aquilo que é essencial e autêntico. A partir disto, podemos afirmar que o historiador mantém maior proximidade com o princípio de razão, pois busca se fundamentar mais pelos acontecimentos fenomênicos. Isto é o que Schopenhauer tem, por objetivo, a intenção de escapar. O poeta, como já foi dito antes, busca se fundamentar pela intuição da objetividade mais elevada da vontade, o que o mantém fora das relações, para além dos fenômenos e do tempo. ${ }^{54}$

A poesia, embora seja um meio de reprodução da ideia de humanidade - algo que não encontramos na realidade fragmentada - e também por ser uma forma que faz agitar nossa imaginação, está acima da história porque é mais instrutiva na apresentação da essência da vida dos homens. A história produz seu conteúdo somente a partir da observação daquilo que o historiador captura da realidade, mas que está sempre ligado à particularidade.

\section{CONSIDERAÇÕES FINAIS}

A afirmação de que a poesia é superior à história pode parecer paradoxal, contudo o meio que melhor nos apresenta a verdade, a originalidade, a essencialidade da humanidade deve ser atribuído à poesia, e não à história. Esta última forma de apresentação da vida, por mais que tente apreender todos os dados da realidade, não logra obter todos estes dados nem muito menos explorar todos os acontecimentos no tempo. Isto ocorre, principalmente, porque segue os acontecimentos fragmentados da vida segundo uma linha cronológica que mostra somente causas e efeitos. Schopenhauer é 
ainda mais incisivo na afirmação da superioridade da poesia, quando diz que a história, por não se aprofundar no quadro geral da humanidade, acaba por se deparar com coisas falsas e assim reproduz mais falsidade que verdade. A poesia tem a capacidade de objetivar parte do seu próprio eu, assim, reproduz aquilo que é essencial a todos nós. 55 Em relação às artes plásticas, a forma poética tem a vantagem de movimentar a imaginação através da ideia. As imagens apresentadas pelas formas plásticas não buscam a nossa imaginação, mas unicamente os olhos ${ }^{56}$. Para Schopenhauer, a poesia não só se difere das artes visuais por essa vantagem, mas também no grau de dificuldade com que o poeta trabalha para atingir a imaginação do leitor. Neste sentido, a poesia se empenha em descrever com detalhes a vida, descreve assim o que há de mais delicado nela. Através dos versos, a forma poética busca desenvolver no imaginário do leitor aquilo que é mais adequado à sua própria individualidade. Este processo também envolve o conhecimento sobre a vida e o seu estado de espírito do próprio leitor: segundo Schopenhauer, a imaginação (a fantasia) "se move mais vividamente (na poesia)" por conta de todos estes detalhes e empenho para atingir quem a lê ou ouve. ${ }^{57}$

As formas de artes plásticas não são capazes de se adaptar à imaginação de quem as observa, ao contrário da poesia. No caso das artes plásticas, por exemplo, o retrato de uma imagem da cena da vida deve satisfazer a todos universalmente. Deste modo, não tem a intenção de respeitar a individualidade de cada espectador na recepção de uma obra plástica. A apreciação destas formas artísticas exige de nós muitas vezes um profundo conhecimento e cultura, mais do que necessitamos para a apreciação, por exemplo, de alguns versos de poesia. Portanto, os versos poéticos “exercem um efeito tão forte, profundo e universal do que imagens e estátuas. Estas muitas vezes deixam as pessoas comuns bastante frias e, em geral, as artes visuais são as que têm o mais fraco efeito". ${ }^{8}$

55 SCHOPENHAUER, 2005, p. 324. 56 SCHOPENHAUER, 2003, p. 202.

57 SCHOPENHAUER, 2014, p. 97.

58 Ibid., 2014, p. 98. 


\section{REFERÊNCIAS BIBLIOGRÁFICAS}

SCHOPENHAUER, A. O mundo como vontade e como representação. Tradução de Jair Barboza.São Paulo: Ed. UNESP, 2005.

O mundo como vontade e representação. Tomo II. Tradução de Eduardo

Ribeiro da Fonseca. Curitiba: Ed. da UFPR, 2014 Metafísica do belo. Tradução, apresentação e notas Jair Barbosa. São Paulo: Editora UNESP, 2003.

BOSSERT, A. Introdução a Schopenhauer. Tradução de Regina Schopke, Mauro Baladi. Rio de Janeiro: Editora Contraponto, 2011.

DIAS, R. M. “Schopenhauer e a Arte”. In: HADDOCK-LOBO, Rafael (org.). Os filósofos e a arte. Rio de Janeiro: Editora Rocco, 2010.

JANAWAY, C. Schopenhauer. Tradução de Adail Ubirajara Sobral. São Paulo: Loyola, 2003.

LEFRANC, J. Compreender Schopenhauer. Tradução de Ephraim Ferreira Alves. Petrópolis: Editora Vozes, 2008.

MACHADO, R. O nascimento do trágico: de Schiller a Nietzsche. Rio de Janeiro: Jorge Zahar Ed., 2006.

YOUNG, J. Schopenhauer. Austin: The Routledge Philosophers, 2005.

WERLE, M. A.; GALÉ, P. (Orgs.). Arte e filosofia no idealismo alemão. São Paulo: Editora Barcarolla, 2009. 